approaching the problem on a wider basis. In 1924 a Committee was constituted to inquire further into, and to report upon, the froghopper pest with the view of its control and ultimate eradication. Among other proposals it led in October 1925 to the Governor appointing a Froghopper Investigation General Committee, and the deliberations of this body are published in the form of Minutes and Proceedings at frequent intervals. 1 The first meeting of this Committee was held in November 1925, and three subcommittees were appointed to deal respectively with (1) agricultural relations ; (2) entomological relations ; and (3) soil relations. Their personnel included planters, officers of the Department of Agriculțre, and members of the staff of the Imperial College of Agriculture. The reports of these sub-committees are considered by a scientific committee which submits recommendations thereon to the general investigation committee alluded to above.

Among the more interesting features recorded or discussed in these Proceedings, it appears that the eggs of the froghopper hatch freely only when the humidity of the atmosphere is greater than 90 per cent of saturation. Some eggs, however, exhibit delayed hatching even though the moisture conditions are entirely favourable, a fact of considerable practical importance, and the cause of these delayed hatchings is now being investigated. No reliable method of eggdestruction has been discovered, but the practice of bare-fallowing well-ploughed land is suggested as a possible measure in that it exposes the eggs to the effects of the sun. The destruction of the nymphs by means of dusting with the proprietary agent 'Cyanogas' appears to offer considerable promise as a practicable and economic method of eradication, but no insecticidal treatment for destroying the adult insects has yet been found. The use of light traps is not considered to have been adequately explored, and, in view of some success having been obtained on certain estates, improved forms of traps are to be tested. The only other entomological measure of importance is that of biological control, and it has been decided to prosecute a vigorous campaign in the near future in order to develop this phase of the work, and with special reference to the study of egg-parasites and predators in the field.

Perhaps one of the most valuable results coming from the froghopper investigation has been its beneficial effect on general agricultural practice. Once it became to be realised that the subject is by no means

1 Minutes and Proceedings of the Froghopper Investigation Committee. Trinidad and Tobago. Parts I-XVI, 1925-1929. Government Printing Office, Trinikad. exclusively entomological, increasing attention has been given to soil conditions and to the factors governing the growth of the crop in general. The fact that a fairly definite correlation exists between susceptibility of canes (especially ratoons) to froghopper attack and degree of soil acidity, has proved a great stimulus to further investigation in this direction. It has been found that (1) a positive correlation exists between the degree of saturation of the soil with lime and cane susceptibility ; (2) soils of blight-free areas are absorptively saturated by lime, or nearly so ; (3) soils of regularly blighted areas are less than 60 per cent saturated ; (4) there is no correlation between gross soil content of lime and susceptibility; and (5) toxic aluminium in the soil often begins to appear when the degree of saturation falls below 60 per cent, and this may greatly increase the susceptibility to blighting.

There seems little doubt that the soils of the regions liable to froghopper attacks are lacking in combined lime (exchangeable calcium), and are therefore usually acidic in reaction. The reason why canes growing on such soils are so liable, whilst canes growing on limesatisfied soils are resistant, to blighting, has not so far been discovered.

The subject of water relations between the soil and crop has received considerable attention. Field observations periodically recorded at three representative stations, for special ' good' and 'bad' plots, have demonstrated profound differences in soil moisture conditions. These differences are reflected in the fluctuations in the moisture-content of the leaves of canes growing on these plots and in the greater transpiration rate for bad-plot canes, leading to more rapid drying out at the time of day when the froghoppers feed. On the biochemical side it appears that the leaves of 'good' canes are much better manufacturers of sugars and proteins than 'bad ' cane leaves, and that their moisture-content is less liable to fluctuation.

Many other problems of plant physiology are touched upon or discussed, and it is evident that much more experimentation, both of the laboratory and field type, is needed if the numerous suggestive indications and facts disclosed in these Proceedings are to be pursued to their practical issue. What is needed is a thorough fundamental ecological study of the cane-plant in relation to its full vigour and to its susceptibility to froghopper attack. It is evident from these reports that these aspects of the subject are fully appreciated, and that due attention to soil conditions and plant growth are more likely ultimately to prove of lasting value to the growers than the application of entomological methods only.

A. D. Imms.

\title{
Annual Conference of the Institut International de Bibliographie.
}

$\mathrm{T}^{\mathrm{T}}$ HE ninth Conference of the Institut International de Bibliographie was held, by kind permission of the governors and Prof. H. L. Callender, in the Imperial College of Science and Technology on Sept. 16 and 17. It was attended by representatives from many of the more important countries of Europe, including the following delegates: Prof. A. F. C. Pollard (President), Mr. Nemec (Czechoslovakia), M. Charles Sustrac (France), Dr. Hesse (Germany), Dr. S. C. Bradford (Great Britain), Mr. Andrau (Holland), Mr. Janički (Switzerland), and the General Secretaries, M. Henri La Fontaine (Belgium) and Mr. F. Donker Duyvis (Holland).

Monday was occupied with meetings of the Council and of the Commission of the Classification. Dr. Bradford gave a report on the discussions on classification during the recent congress of librarians in Italy.
He outlined a scheme whereby, by the general adoption by bibliographical agencies of a standard classification, a comprehensive subject-index to published information of all kinds could be realised at once, with the saving of untold amounts of useless effort now wasted in repetition of previous work. It appeared that no other classification than the Decimal Classification, elaborated during more than thirty years by the collaborators of the Brussels Institute, came into discussion, and this classification is now being adopted as a standard by institutions of all kinds throughout the world.

Mr. Donker Duyvis, as secretary of the Commission of the Decimal Classification, gave his report on the present state of the printing of the new manual of the classification. About 1500 pages have now been printed, which brings the manual to the end of the

No. 3127, VoL. 124] 
main divisions. The auxiliary tables and relative index remain to be printed. It was pointed out that the new manual has a provisional character and will serve as a basis for future enlarged editions. Various important improvements have been made and the theory of classification has been worked out in various respects and put into practice. The new manual is very comprehensive and provides at least a general class-number for practically every topic of human knowledge. Parts of the manual are being translated into five different languages. A mechanism is in existence for securing new sub-divisions as required, so as to keep the classification up-todate.

The general assembly was opened on Tuesday, Sept. 17, with an address by the president, Prof. Pollard. In view of the visitors present, who included Sir Henry Lyons, Director of the Science Museum, as the representative of the Royal Society, Prof. Pollard first explained the function and work of the Institut. This function, he said, is, in effect, the economic distribution of means by which the information upon any given matter contained in the world's literature may be exhaustively extracted and immediately brought to light. The comparatively small but rapidly increasing literature of science is fed both by genius and exceptional intellects, which are in a class by themselves, and by those who labour in association. To the former the work of the Institut does not universally appeal, but the importance of bibliography to the latter is evidenced by the laboured bibliographies which are compiled by nearly all associative bodies concerned with scientific research and technological developments. For want of organised bibliography, the history of science and technology reveals much useless repetition and wasted effort, and even the circumscribed work of gifted intellects suffers from a neglect of bibliography.
The aim of the Institut International de Bibliographie is to provide the golden key which unlocks the treasure-house of the document, and is embodied in the study and application of bibliographical method. Daughter societies or branches of the Institut are being established in all countries of the world for the purpose of collecting, under the control of the Institut, in the most economical manner, and distributing to the student, the references to published information. It has been estimated that, if the work and labour now put into existing bibliographies were ordered and controlled, the ideal of a comprehensive index to the printed record might be realised now.

Prof. Pollard enumerated a number of important scientific societies, research associations, and bureaux in Great Britain which have adopted the methods of the Institut International de Bibliographie within the past year, chiefly through the activities of members of the British Society for International Bibliography, which has its headquarters at the Imperial College of Science and Technology, and is affiliated to the Institut. This is only a part of the first step that must be taken in order that the massed attack upon literature, which is gradually being organised by the Institut through the agency of affiliated bibliographical societies situated in civilised countries, may take effect to the lasting benefit of mankind.

An interesting discussion followed on the application of the Universal Decimal Classification and other schemes, in which the principal speakers were M. La Fontaine, Mr. Donker Duyvis, Mr. Rottenburg, Dr. Griffin, Mr. Lancaster Jones, Prof. Pollard, and Dr. Bradford. The discussion emphasised the important points that no unaided individual, however expert in a special subject, is capable in elaborating a satisfactory scheme of classification, and that a comprehensive index to published information can only be realised by the co-operation of many agencies using a standardcode.

\section{Aeronautical Research in Great Britain.}

THE spectacular setting of the Schneider Cup Race and the terrific speeds of $360 \mathrm{~m}$.p.h. at which the British pilots lapped the course tend to obscure the enormous mass of scientific work of which this fine achievement is one of the more dramatic illustrations. It is on the incredible speeds attained that the excited layman focuses his attention-the mere outward and visible sign-but the problems of engine design, of structural strength under the enormous stresses in turning, of stability and controllability, of the aerodynamic properties of propellers and the other exposed aeroplane parts - these lie masked behind this single item of speed performance.

How the study of these problems is organised and their solution slowly attained is once more made evident in the Annual Report of the Aeronautical Research Committee, for the year 1928-29.1

The fields of research pursued by the Committee cover such subjects as aerodynamics, stability and control, engines, alloys, elasticity and fatigue, while in addition a large degree of consideration has been devoted to the problems of interference of body parts and to wing flutter. New researches in thes? matters have been initiated, while matters dealt with in previous annual reports have reached a more advanced stage. Amongst these are the lateral control of aeroplanes at low speeds; auto slots, for example, have been fitted to a large number of service aircraft ; pilot planes are in use on experimental aircraft, and various means of putting a slot out of action if

1 Aeronautical Research Committee. Report for the year 1928-29. Pp. 63. (London: H.M. Stationery Office, 1929.) $2 s$. necessary, when used in conjunction with an aileron, are under trial. An important research on flutter has been completed, while researches on sleeve valve engines, on engines when highly supercharged, and on compression ignition engines are progressing rapidly.

One of the problems that has received much attention during the past year is the intensive improvement of aeroplane performance. A wide disparity still exists between the total head resistance of an ideal aeroplane the drag of which is entirely due to skin friction and that of conventional aeroplanes of present design. Attempts to reduce this large difference constitute the object of researches already initiated, and it is anticipated that much of the work of the Committee in the near future will be concerned with this problem, as there is in this field considerable scope for research which should have valuable consequences.

Arising out of this, further light is being thrown on the interesting problem of 'scale effect', for which an allowance has to be made in the prediction of full-scale resistance from model data on good stream-line bodies. It appears to be the case that much of the uncertainty in the passage from model to full scale is due to the fact that in the former case the flow is not so completely turbulent as in the latter, so that the prediction will be less liable to error if the flow in the wind tunnel can be rendered sufficiently turbulent. This question of turbulence, including both the mechanism of its origin and its general effect on performance, is considered a matter of primary importance. Thus the practical problems of flight are continually being reduced to their dependence on pure research. 